\title{
Acid-base interactions in some isoquinoline and quinazoline amino derivatives
}

\author{
Wojciech Zieliński and Agnieszka Kudelko* \\ Department of Organic Technology and Petrochemistry \\ Silesian University of Technology \\ Ul. Krzywoustego 4, PL-44101 Gliwice, Poland \\ E-mail: kudelkoa@zeus.polsl.gliwice.pl
}

\section{Dedicated to Professor Lubor Fisera on the occasion of his $60^{\text {th }}$ birthday}

(received 24 Sept 04; accepted 21 Dec 04; published on the web 23 Dec 04)

\begin{abstract}
Few groups of substituted 1-aminoisoquinoline, 4-amino- and 2,4-diaminoquinazoline derivatives have been examined in order to find general relationships between the basicity and a kind of substituent. $p K_{a}$ Values have been determined for these compounds and correlated with the original Hammett $\sigma_{m}$ and $\sigma_{p}$ constants. They clearly showed that the steric effects of the bulky substituents neighbouring the protonated ring nitrogen atom influence the electron transfer in such arrangements. Different tendencies in the electron transfer caused by the same groups in the position 1 of isoquinoline and position 4 of quinazoline have been also disscused. The $\rho$ value, single crystal X-ray analysis, ${ }^{15} \mathrm{~N}-\mathrm{NMR}$ spectra and MNDO calculations give evidence about the electronic effects and the preferential site of protonation in such arrangements.
\end{abstract}

Keywords: 1-Aminoisoquinolines, 4-aminoquinazolines, 2,4-diaminoquinazolines, $p K_{a}$ dissociation constants, $p K_{a} v s \sigma$ correlation, basicity, steric effect

\section{Introduction}

Compounds containing a fused quinazoline or isoquinoline ring belong to a broad class of compounds which has received a considerable attention over the past years due to their wide range of biological activities. ${ }^{1,2}$ Some of aminoquinazoline derivatives were found to be inhibitors of the tyrosine kinase $\mathrm{e}^{3,4}$ or dihydrofolate reductase enzymes ${ }^{5,6}$ so they work as potent anticancer agents. They are also used to work out medicines against hypertension, malaria and to fight infections involving AIDS. ${ }^{7}$ Some isoquinoline derivatives are known due to the centralnervous-system activity which they show. ${ }^{8}$ 
A biological activity of the compound strongly depends on acid-base interactions which is an addition to behaviour associated with its permeability through cell membranes and its spatial structure. ${ }^{1}$ That is why an analysis of acid-base equilibrium and factors influencing these equilibrium are very important questions. The matter of this study is the analysis of acid-base interactions of the three groups of compounds: 1-aminoisoquinolines, 4-aminoquinazolines and 2,4-diaminoquinazolines. Such different compounds are characterized by the common amidine function built in the aromatic ring and a presence of two basic centers at least connecting with free electron pairs of endocyclic and exocyclic nitrogen atoms. If the basicity of 1 -aminoisoquinolines is well defined in so far $^{9-13}$ it is still controversial question in the case of 4amino- or 2,4-diaminoquinazolines. It is proved that the first protonation of the nitrogen heterocycles with the amino substituent takes place unexpectedly at the ring nitrogen atom. In contrast to the first proton addition which occurs in dilute acid solutions, the second protonation needs strong acids because the basicity of the monoprotonated form is relatively small. An introduction of the second electronwithdrawing nitrogen atom to the ring decreases the basicity of the compound in respect to isoquinoline moiety. Generally, aminoquinazolines ${ }^{1,4,15}$ are weaker bases in comparison to their isoquinoline counterparts. ${ }^{16}$ An interpretation of $p K_{a}$ dissociation constants of some quinazolines determined in water solutions is complicated in many cases by the covalent hydration of water molecule across a 3,4-double quinazoline bond. ${ }^{15,17}$ The observed values are lower even about 2 units in $p K_{a}$ scale in respect to the values of the anhydrous species. ${ }^{14}$ The 4 position of quinazoline is directly involved in the reversible water addition so it was proved that the steric and inductive effects of the substituents in this position have a marked effect on the covalent hydration. ${ }^{18}$ The introduction of the amino group in the 2 or 4 position of quinazoline decreases hydration in cation considerably. The covalent hydration is almost prevented if hydrogen atoms of the amino group in the mentioned positions are replaced by the electrondonating substituents such as $\mathrm{CH}_{3}{ }^{15}$

Few groups of aminoisoquinolines and mono- and diaminoquinazolines (Scheme 1) were analyzed to find general relationships between the basicity and a kind of substituent.

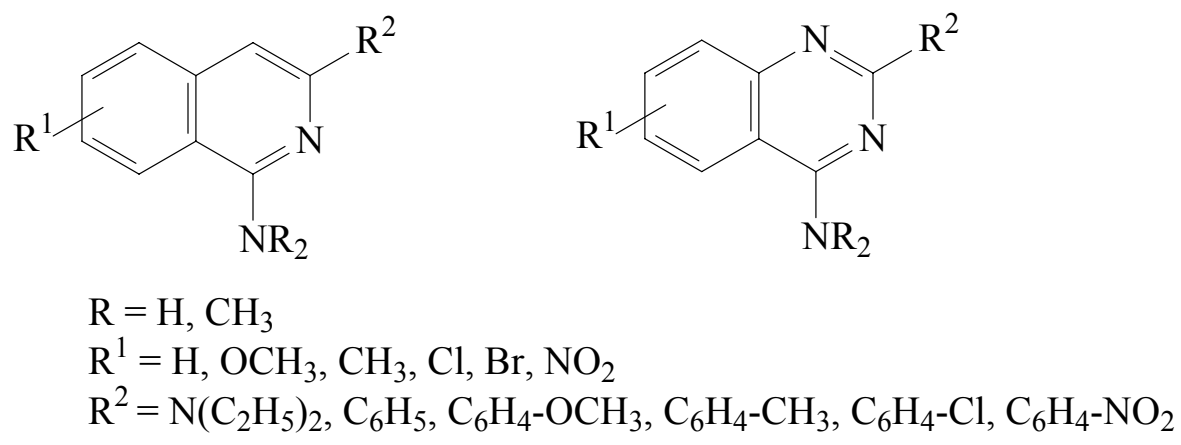

\section{Scheme 1}


There were 3-methyl-1-(N,N-dimethylamino)isoquinoline and 3-( $N, N$-diethylamino)-1-( $N, N$ dimethylamino)isoquinoline derivatives substituted in the position 6 or 7 with electron-donating and withdrawing groups, 1-amino-3-( $N, N$-diethylamino)isoquinoline and 1-amino-3methylisoquinoline in the first studied group. Four series of quinazoline derivatives such as: 4( $N, N$-dimethylamino)-2-phenylquinazoline, $\quad$ 4-amino-2-phenylquinazoline, $\quad$ 2- $(N, N$ diethylamino)-4-( $N, N$-dimethylamino)quinazoline, $\quad$ 4-amino-2-( $N, N$-diethylamino $)$ quinazoline substituted in the position 6 or 7 with electron-donating and withdrawing groups and a series of 2-aryl-4-( $N, N$-dimethylamino)quinazolines were examined in the second group. We have determined the influence of the substituents attached both to benzene and pyridine or pyrimidine fragments on the basicity of the parent system. We have also disscused the electronic effects of the bulky substituents at the 1-position of isoquinoline and at 4-position of quinazoline which in our opinion lead to untypical correlations between $p K_{a}$ values and Hammett $\sigma$ constants.

\section{Results and Discussion}

\section{Preparation and $p K_{a}$ determination of 1-aminoisoquinoline, 4-amino- and 2,4- diaminoquinazoline derivatives}

3-Methylisoquinolines were prepared by a known method from the substituted at the benzene ring benzyl-methyl ketones in the reaction with $N, N$-dimethylcyanamide or cyanamide with the use of $\mathrm{TiCl}_{4}$ as the Lewis acid catalyst. ${ }^{19-23}$ The rest of 3-(N,N-diethylamino)isoquinolines were synthesized in the reaction of the appropriate $N, N$-diethylarylacetamides with $\mathrm{POCl}_{3}$ and then with $N, N$-dimethylcyanamide or cyanamide. $^{24}$ Aminoquinazolines were prepared from $N$ arylbenzamides or $N$-phenyl- $N$ ', $N$ '-diethylureas in the reaction with $\mathrm{PCl}_{5}$ and then with $N, N$ dimethylcyanamide or cyanamide in the presence of $\mathrm{TiCl}_{4} \cdot{ }^{25-30}$ The determination of the $p K_{a}$ dissociation constants was performed according to the spectrophotometric method ${ }^{31}$ of Albert and Serjeant in $50 \%$ aqueous methanol solution $\left(10^{-5} \mathrm{M}\right.$, room temperature) due to the low solubility of the compounds in water and characteristic UV spectrum (Table 1, 3, 4). Absorption maxima of the isoquinoline and quinazoline ions were selected as analytical wavelengths, bearing in mind their considerable shifts relative to the maxima of the non-protonated forms. The $p K_{a}$ values determined in aqueous-methanolic solution are lower about $0.6 p K_{a}$ units comparing with those determined in aqueous solution which is the result of different ionic products of these solvents. 
Table 1. Dissociation constants $p K_{a}$ of isoquinoline bases<smiles>[R]c1ccc2cc([R])nc([R])c2c1</smiles>

\begin{tabular}{|c|c|c|c|c|c|}
\hline Product & $R:$ & $R^{l}:$ & $R^{2}$ & $\lambda_{\mathrm{ANAL}}[\mathrm{nm}]$ & $p K_{a}^{*}$ \\
\hline 1 & $\mathrm{H}$ & $\mathrm{H}$ & $\mathrm{H}$ & 261.0 & $4.79 \pm 0.06$ \\
\hline 2 & $\mathrm{H}$ & $\mathrm{NH}_{2}$ & $\mathrm{CH}_{3}$ & 275.0 & $7.27 \pm 0.03$ \\
\hline 3 & $\mathrm{H}$ & $\mathrm{C}_{6} \mathrm{H}_{5}$ & $\mathrm{CH}_{3}$ & 353.0 & $4.99 \pm 0.08$ \\
\hline 4 & $\mathrm{H}$ & $\mathrm{CH}_{3}$ & $\mathrm{CH}_{3}$ & 353.0 & $6.30 \pm 0.12$ \\
\hline 5 & $\mathrm{H}$ & $\mathrm{NH}_{2}$ & $\mathrm{~N}\left(\mathrm{C}_{2} \mathrm{H}_{5}\right)_{2}$ & 246.0 & $7.24 \pm 0.18$ \\
\hline $6 \mathbf{a}$ & $\mathrm{H}$ & $\mathrm{N}\left(\mathrm{CH}_{3}\right)_{2}$ & $\mathrm{CH}_{3}$ & 308.0 & $6.29 \pm 0.07$ \\
\hline $6 \mathbf{b}$ & $6-\mathrm{OCH}_{3}$ & $\mathrm{~N}\left(\mathrm{CH}_{3}\right)_{2}$ & $\mathrm{CH}_{3}$ & 344.0 & $6.75 \pm 0.04$ \\
\hline $6 c$ & $7-\mathrm{OCH}_{3}$ & $\mathrm{~N}\left(\mathrm{CH}_{3}\right)_{2}$ & $\mathrm{CH}_{3}$ & 284.0 & $6.23 \pm 0.10$ \\
\hline 6d & $6-\mathrm{CH}_{3}$ & $\mathrm{~N}\left(\mathrm{CH}_{3}\right)_{2}$ & $\mathrm{CH}_{3}$ & 309.0 & $6.74 \pm 0.05$ \\
\hline $6 e$ & 7- $\mathrm{CH}_{3}$ & $\mathrm{~N}\left(\mathrm{CH}_{3}\right)_{2}$ & $\mathrm{CH}_{3}$ & 293.0 & $6.28 \pm 0.02$ \\
\hline $6 f$ & $6-\mathrm{Cl}$ & $\mathrm{N}\left(\mathrm{CH}_{3}\right)_{2}$ & $\mathrm{CH}_{3}$ & 315.0 & $5.69 \pm 0.07$ \\
\hline $6 g$ & $7-\mathrm{Cl}$ & $\mathrm{N}\left(\mathrm{CH}_{3}\right)_{2}$ & $\mathrm{CH}_{3}$ & 299.0 & $5.40 \pm 0.12$ \\
\hline $6 h$ & $7-\mathrm{Br}$ & $\mathrm{N}\left(\mathrm{CH}_{3}\right)_{2}$ & $\mathrm{CH}_{3}$ & 323.0 & $5.60 \pm 0.09$ \\
\hline $7 \mathbf{a}$ & $\mathrm{H}$ & $\mathrm{N}\left(\mathrm{CH}_{3}\right)_{2}$ & $\mathrm{~N}\left(\mathrm{C}_{2} \mathrm{H}_{5}\right)_{2}$ & 284.0 & $6.70 \pm 0.12$ \\
\hline $7 b$ & $6-\mathrm{OCH}_{3}$ & $\mathrm{~N}\left(\mathrm{CH}_{3}\right)_{2}$ & $\mathrm{~N}\left(\mathrm{C}_{2} \mathrm{H}_{5}\right)_{2}$ & 289.0 & $7.15 \pm 0.12$ \\
\hline $7 c$ & $7-\mathrm{OCH}_{3}$ & $\mathrm{~N}\left(\mathrm{CH}_{3}\right)_{2}$ & $\mathrm{~N}\left(\mathrm{C}_{2} \mathrm{H}_{5}\right)_{2}$ & 210.0 & $6.61 \pm 0.12$ \\
\hline 7d & $6-\mathrm{Cl}$ & $\mathrm{N}\left(\mathrm{CH}_{3}\right)_{2}$ & $\mathrm{~N}\left(\mathrm{C}_{2} \mathrm{H}_{5}\right)_{2}$ & 253.0 & $6.45 \pm 0.12$ \\
\hline $7 e$ & 7-Cl & $\mathrm{N}\left(\mathrm{CH}_{3}\right)_{2}$ & $\mathrm{~N}\left(\mathrm{C}_{2} \mathrm{H}_{5}\right)_{2}$ & 296.0 & $6.14 \pm 0.12$ \\
\hline
\end{tabular}

* The measurements were made in 50\% methanol-water solution at room temperature.

\section{Basicity of 1-aminoisoquinoline derivatives}

The results show that electrondonating groups in positions 6 or 7 of the isoquinoline ring cause an increase compared with the $p K_{a}$ of the parent compound $(\mathrm{R}=\mathrm{H})$; the opposite holds for electronwithdrawing groups. The difference between the basicity of 6-R and 7-R isomers were caused mainly by the possibility of the substituent-reaction centre coupling but also by steric and electronic effects of the substituents in the 1-isoquinoline or - which will be shown later - 4quinazoline positions.

Generally, 1-aminoisoquinolines are stronger bases than the corresponding isoquinolines (Table 1). This is the result of the introduction in the position 1 of isoquinoline the strongly electrondonating amino or dimethylamino group whose free electron pair participates in the coupling with the ring $\pi$ electrons. This leads to the increasing of the electron density of the ring nitrogen atom. 6-R-Isoquinolines substituted with the electrondonating groups are stronger bases than their 7-R isomers which is caused mainly by the possibility of the substituent-ring nitrogen 
atom coupling. The determined $p K_{a}$ values were correlated with appropriate Hammett $\sigma$ constants. ${ }^{32}$ According to Charton's suggestions who has examined the application of different substituent constants in aromatic systems ${ }^{33}$ we have used the original Hammett $\sigma_{m}$ and $\sigma_{p}$ constants. The least squares method was applied and each correlation was characterized by a correlation coefficient $\mathrm{r}$. The results of $p K_{a}$ versus $\sigma$ correlation for two isoquinoline series (6a-h, 7a-e) are presented in the Table 2 and the best correlations are visualized at the Figure 1.

Analyzing these data it was found that much better correlations for 6-R substituted isoquinoline derivatives were obtained when $\sigma_{p}$ Hammett constants were used whereas for 7-R substituted derivatives the correlations are better for $\sigma_{m}$ Hammett constants (Table 2, Figure 1). The correlation of $p K_{a}$ for 7-R substituted isoquinoline derivatives with $\sigma_{m}$ constants and 6-R substituted derivatives with $\sigma_{p}$ constants is consistent with Charton's suggestions ${ }^{33}$ and investigations on electron interactions in monosubstituted alternateng systems. ${ }^{34}$

Table 2. Results of $p K_{a}$ vs $\sigma$ correlations for two 1-(N,N-dimethylamino)isoquinoline (6a-h, 7ae) series

\begin{tabular}{llllllll}
\hline Entry & Product & Correlation type & Equation & $\boldsymbol{p} \boldsymbol{K}_{\boldsymbol{a}}=\boldsymbol{\rho} \boldsymbol{\sigma}+\boldsymbol{p} \boldsymbol{K}_{\boldsymbol{0}}$ & $\mathrm{S}^{\mathrm{a})}$ & $\mathrm{r}^{\mathrm{b})}$ & $\mathrm{n}^{\mathrm{c})}$ \\
\hline $1^{\mathrm{d})}$ & 6a-h & 6-R- $\sigma_{\mathrm{p}}, 7-\mathrm{R}-\sigma_{\mathrm{m}}$ & $p K_{a}=-2.017 \sigma+6.274$ & 0.142 & 0.966 & 8 \\
2 & 6a-h & 6-R- $\sigma_{\mathrm{m}}, 7-\mathrm{R}-\sigma_{\mathrm{p}}$ & $p K_{a}=-1.384 \sigma+6.199$ & 0.442 & 0.597 & 8 \\
$3^{\mathrm{d})}$ & 7a-e & 6-R- $\sigma_{\mathrm{p}}, 7-\mathrm{R}-\sigma_{\mathrm{m}}$ & $p K_{a}=-1.506 \sigma+6.745$ & 0.009 & 0.991 & 5 \\
4 & 7a-e & 6-R- $\sigma_{\mathrm{m}}, 7-\mathrm{R}-\sigma_{\mathrm{p}}$ & $p K_{a}=-0.433 \sigma+6.649$ & 0.501 & 0.285 & 5 \\
\hline
\end{tabular}

${ }^{a} \mathrm{~S}$ - residual sum of squares; ${ }^{\mathrm{b}} \mathrm{r}$ - correlation coefficient; ${ }^{\mathrm{c}} \mathrm{n}$ - number of data points used.

${ }^{\mathrm{d}}$ best correlations presented at the Figure1.

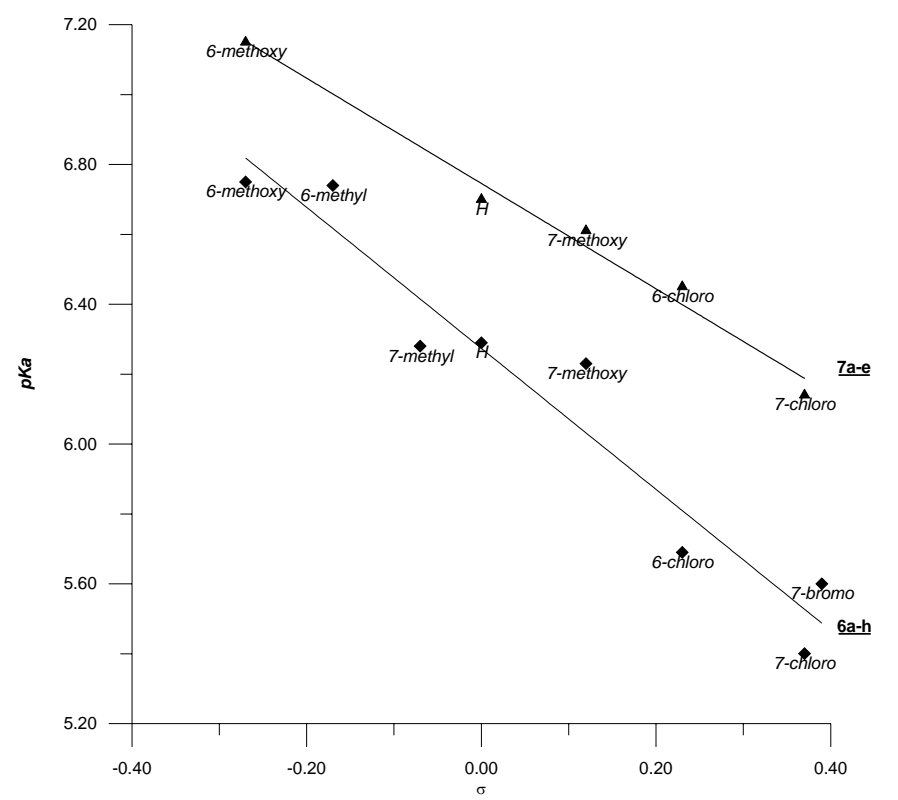

Figure 1. Correlation of Hammett's constants with $p K_{a}$ for isoquinolines (6a-h, 7a-e). 
A special attention should be paid to the influence of the substituents in the position 1 of 3-methylisoquinoline on the basicity of the arrangement. It is quite complicated to interpret the interaction of substituents in ortho position since the equilibrium achieved between field, induction, resonance and steric effects is complex. ${ }^{32}$ The primary steric effect which is connected with the interaction of the substituent in 1 position with free electron pair of the ring nitrogen atom should not be of a great importance. ${ }^{35}$ Therefore, the effect of substituents on a reaction centre can be mainly explained by the induction and resonance effects. It can be supposed that in case of small groups like $\mathrm{CH}_{3}(4)$ and $\mathrm{NH}_{2}(2)$ in the 1-isoquinoline position the resonance effect dominates and a higher basicity is observed. In contrast, the derivatives with phenyl (3) or dimethylamino (6a) groups behave quite unexpectedly. For such compounds a considerable secondary steric effect ${ }^{35}$ related to the interaction of bulky substituents in position 1 of isoquinoline with hydrogen in position 8 can not be neglected. This interaction leads to a twist of the bulky group $\left(\mathrm{C}_{6} \mathrm{H}_{5}, \mathrm{~N}\left(\mathrm{CH}_{3}\right)_{2}\right)$ in 1-position from the ring plane and finally to the electron coupling limitations (Scheme 2). It is not observed for small substituents $\left(\mathrm{CH}_{3}, \mathrm{NH}_{2}\right)$ which are left untwisted in the ring plane.

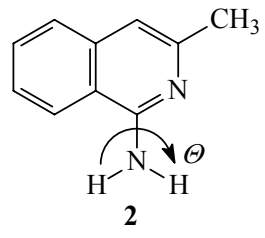

$p K_{a}=7.27$

$\Theta=11^{\circ}$

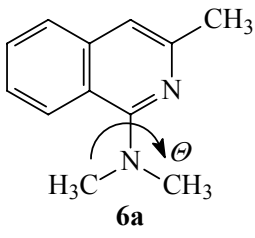

$p K_{a}=6.29$

$\Theta=73^{\circ}$

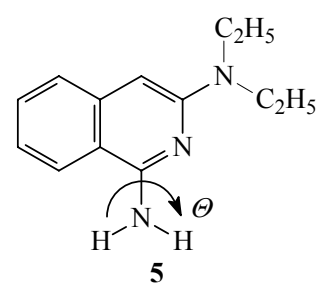

$p K_{a}=7.24$

$\Theta=5^{\circ}$

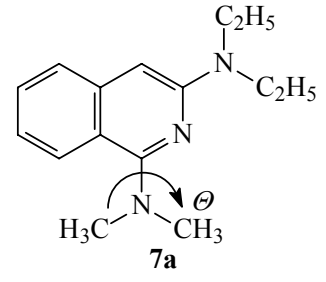

$\begin{aligned} p K_{a} & =6.70 \\ \Theta & =110^{\circ}\end{aligned}$

\section{Scheme 2}

As the result the resonanse effect is reduced in comparison with the inductive one. It is estimated that the interaction between a substituent in the ortho position and the ring nitrogen atom is in $70 \%$ of the induction nature. ${ }^{35}$ That is why 3-methyl-1- $(N, N-$ dimethylamino)isoquinoline (6a) and 3-(N,N-diethylamino)-1-( $N, N$-dimethylamino)-isoquinoline (7a) are weaker bases than 1-amino-3-methyisoquinoline (2) in spite of the fact that the $\mathrm{N}\left(\mathrm{CH}_{3}\right)_{2}$ and $\mathrm{N}\left(\mathrm{C}_{2} \mathrm{H}_{5}\right)_{2}$ groups are more electrondonating than $\mathrm{NH}_{2}$. Similarly to $6 \mathbf{a}$ and $7 \mathbf{a}$ isoquinolines behaves 1-phenyl-3-methylisoquinoline (3). The replacement of the methyl group in the position 3 of the isoquinoline with strongly electrondonating diethylamino group leads to unexpected changes in the basicity. It is known that two ortho isomers of aminoisoquinoline behave quite different. $^{16}$ 3-Aminoisoquinoline is considerably weaker base than 1-aminoisoquinoline (Table 1). This decrease in the base strength is attributed to the lower contribution of the 8 structure in the resonance hybride (Scheme 3). 

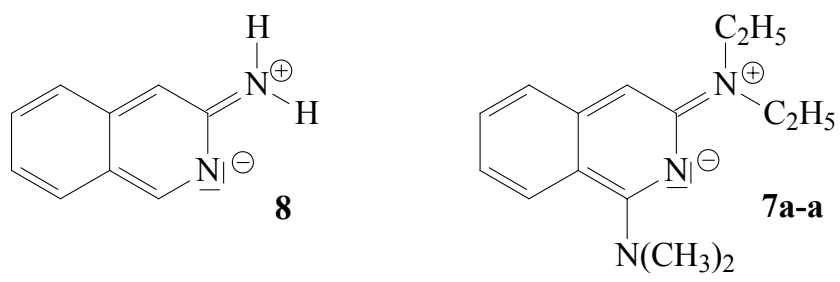

\section{Scheme 3}

If such foundation is right the induction effect of the substituent in position 3 should be mainly responsible for the basicity. According to this isoquinoline 7a should be less basic than isoquinoline 6a because $\mathrm{N}\left(\mathrm{C}_{2} \mathrm{H}_{5}\right)_{2}$ and $\mathrm{CH}_{3}$ groups have got the opposite induction effects. Meanwhile, we could observe different effects according to the character of the substituent in the position 3. It is not of the great importance in the case of 1-aminoisoquinolines unsubstituted at the amino group $(\mathbf{2}, \mathbf{5})$ where its free electron pair couples with ring $\pi$ electrons. A replacement of the methyl group in the considered position by diethylamino group increases the basicity of the arrangement in these isoquinolines which have the bulky and twisted from the ring plane dimethylamino group at position 1 . The mesomeric effect $(+M)$ of diethylamino group leads probably to the higher contribution of the structure 7a-a in the resonance hybride (Scheme 3 ) and 3-(N,N-diethylamino)-1-(N,N-dimethylamino)isoquinoline (7a) is considerably stronger base as expected.

\section{Basicity of 4-amino- and 2,4-diaminoquinazoline derivatives}

4-Aminoquinazolines have three potential protonation sites and it is not established which one is the most susceptible to the proton attack till now. In order to identify it we have proceeded in two ways. Correlation analysis of $p K_{a}$ dissociation constants with the Hammett $\sigma$ constants constitutes an indirect approach whereas single crystal X-ray analysis of the protonated compounds and ${ }^{15} \mathrm{~N}-\mathrm{NMR}$ analysis represent direct solid state and solution approaches. Single crystal X-ray analysis of 4-( $N, N$-dimethylamino)-2-( $p$-methoxyphenyl)quinazoline hydrochloride $(\mathbf{1 3 b} \cdot \mathbf{H C l})$ proves that the protonation occurs on the nitrogen atom at the 1 position in the solid state. $^{25}$ The material crystallizes with two organic molecules, two ionic $\mathrm{HCl}$ and one water molecule per asymetric unit in a cell. Details of bonding are substantially the same for two independent molecules. There is no hydrogen bonding interaction involving the second endocyclic nitrogen atom N3 or the exocyclic nitogen atom of the dimethylamino group C4$\mathrm{N}\left(\mathrm{CH}_{3}\right)_{2}$. It proves besides that the covalent hydration of the water molecule across a 3,4-double quinazoline bond does not exist here.

However, ${ }^{15} \mathrm{~N}-\mathrm{NMR}$ measurements of 4 -( $N, N$-dimethylamino $)-2$-phenyl- quinazoline trifluorineacetate $\left(\mathbf{1 3 a} \cdot \mathbf{C F}_{3} \mathbf{C O O H}\right)$ indicate that the protonation process in the solution is more dynamic. $^{25}$ There are three signals observed in the spectrum of the free quinazoline 13a registered in chloroform. Two of them come from the ring nitrogen atoms: N1 at $\delta=-137.675$ and $\mathrm{N} 3$ at $\delta=-144.551 \mathrm{ppm}$ and the third one from the amino nitrogen atom at the 4-quinazoline 
position: $\mathrm{N}-\mathrm{C} 4$ at $\delta=306.062 \mathrm{ppm}$. The protonation of the arrangement causes great changes of chemical shifts. There are only two signals observed in the spectrum of the salt $\mathbf{1 3 a} \cdot \mathbf{C F} \mathbf{C} \mathbf{C O O H}$ : the intermediary one for the atoms N1 and N3 at $\delta=154.374 \mathrm{ppm}$ and the second one of N-C4 shifted about $35 \mathrm{ppm}$ in respect to the free quinazoline. Spectral analysis indicates that there is a fast hydrogen exchange between the two endocyclic nitrogen atoms and that a possitive charge is concentrated on the exocyclic nitrogen atom of the dimethylamino group (Scheme 4). Thus structures 13a-a and 13a-b dominate.

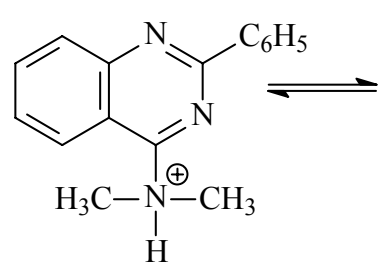

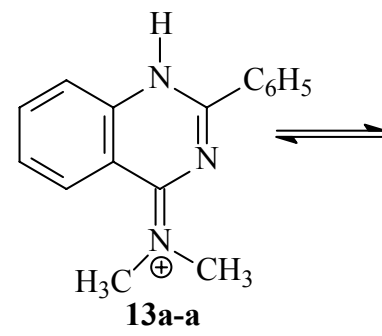

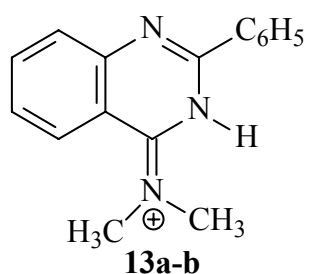

\section{Scheme 4}

In the ${ }^{1} \mathrm{H}-\mathrm{NMR}$ spectrum of $\mathbf{1 3 a} \cdot \mathbf{C} \mathbf{F}_{\mathbf{3}} \mathbf{C O O H}$, an $\mathrm{N}-\mathrm{H}$ signal has been observed at $11.3 \mathrm{ppm}$. The coupling constant $\left(J^{15} \mathrm{~N}-{ }^{1} \mathrm{H}=5 \mathrm{~Hz}\right)$ between the exocyclic nitrogen atom and the proton in the ${ }^{15} \mathrm{~N}-\mathrm{NMR}$ also testifies to the occurrance of only a weak interaction of the proton and the exocyclic nitrogen atom. ${ }^{36}$ This observation is in contrast to the protonation preference observed in 4-aminopyrimidine salts. ${ }^{37}$

Within two groups of 4-amino- and 2,4-diaminoquinazoline derivatives substituted in the position 6 or 7 with electron-donating and withdrawing groups (Table 3, 4, Scheme 5) the strongest bases are quinazolines with the diethylamino substituent at the position 2 (12a-g).
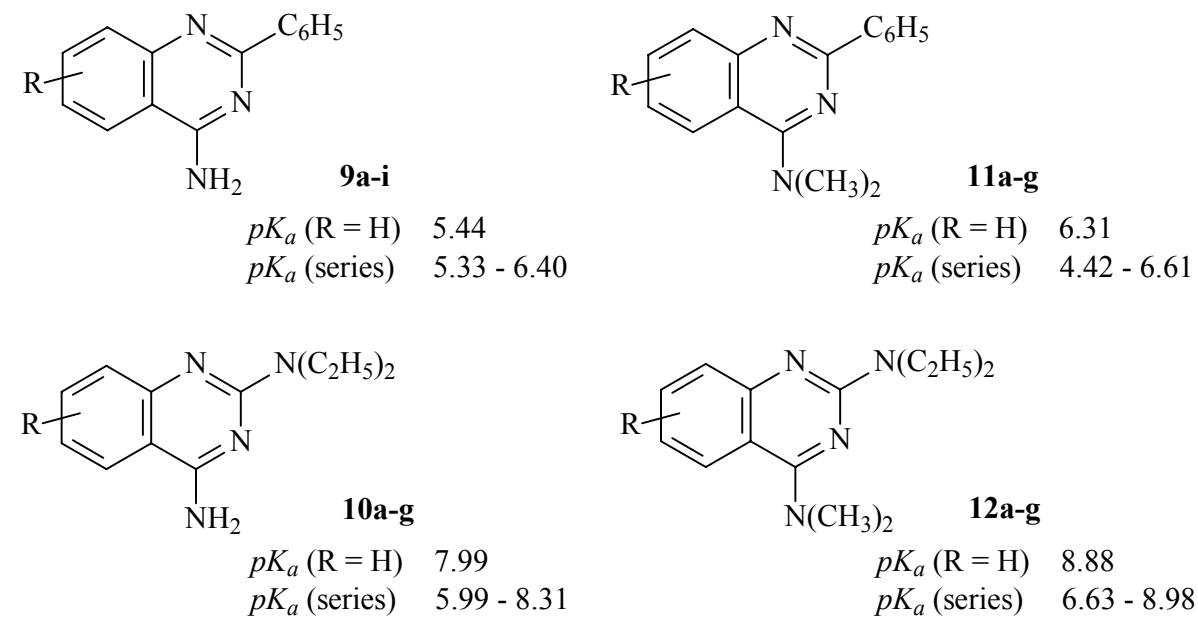

\section{Scheme 5}


Table 3. Dissociation constants $p K_{a}$ of two 4-aminoquinazoline series (9a-i, 10a-g)
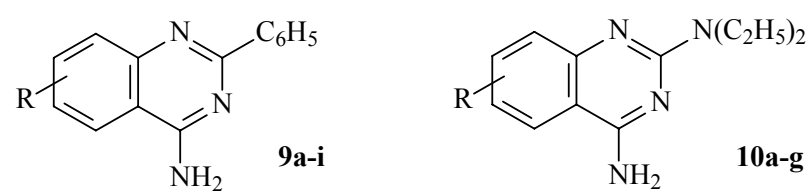

\begin{tabular}{|c|c|c|c|}
\hline Product & $R:$ & $\lambda_{\mathrm{ANAL}}[\mathrm{nm}]$ & $p K_{a}^{*}$ \\
\hline $9 \mathbf{a}$ & $\mathrm{H}$ & 262.0 & $5.44 \pm 0.13$ \\
\hline $9 b$ & $6-\mathrm{CH}_{3}$ & 303.5 & $5.16 \pm 0.18$ \\
\hline $9 \mathrm{c}$ & 7- $\mathrm{CH}_{3}$ & 325.0 & $5.53 \pm 0.07$ \\
\hline 9d & $6-\mathrm{OCH}_{3}$ & 308.5 & $5.33 \pm 0.08$ \\
\hline $9 e$ & 7- $\mathrm{OCH}_{3}$ & 324.5 & $5.62 \pm 0.07$ \\
\hline $9 f$ & $6-\mathrm{NO}_{2}$ & 322.0 & $4.54 \pm 0.27$ \\
\hline $9 \mathrm{~g}$ & 7- $\mathrm{NO}_{2}$ & 259.0 & $4.27 \pm 0.18$ \\
\hline $9 \mathrm{~h}$ & $6-\mathrm{Br}$ & 248.0 & $4.78 \pm 0.08$ \\
\hline $9 \mathbf{i}$ & $6-\mathrm{Cl}$ & 277.7 & $4.98 \pm 0.06$ \\
\hline $10 \mathrm{a}$ & $\mathrm{H}$ & 236.4 & $7.79 \pm 0.15$ \\
\hline $10 \mathrm{~b}$ & $6-\mathrm{OCH}_{3}$ & 251.2 & $7.82 \pm 0.09$ \\
\hline $10 \mathrm{c}$ & 7- $\mathrm{OCH}_{3}$ & 254.8 & $8.31 \pm 0.05$ \\
\hline 10d & $6-\mathrm{Cl}$ & 270.6 & $6.98 \pm 0.17$ \\
\hline $10 \mathrm{e}$ & 7-Cl & 261.0 & $7.09 \pm 0.12$ \\
\hline $10 f$ & $6-\mathrm{NO}_{2}$ & 270.0 & $6.05 \pm 0.08$ \\
\hline $10 \mathrm{~g}$ & 7- $\mathrm{NO}_{2}$ & 268.4 & $5.99 \pm 0.21$ \\
\hline
\end{tabular}

* The measurements were made in 50\% methanol-water solution in room temperature.

The introduction of the strongly electron donating dimethylamino group in the position 4 changes the basicity considerably.

The values of $p K_{a}$ dissociation constants of 4-(N,N-dimethylamino)quinazolines differ from their 4-aminoquinazoline counterparts at about $1 p K_{a}$ unit. This is opposite to the behaviour of isoquinolines (1-7e, Table 1) where the derivatives with bulky substituents in 1-isoquinoline position $\left(\mathrm{R}^{1}=\mathrm{N}\left(\mathrm{CH}_{3}\right)_{2}, \mathrm{C}_{6} \mathrm{H}_{5}\right)$ were considerably weaker bases than those with small substituents $\left(\mathrm{R}^{1}=\mathrm{NH}_{2}, \mathrm{CH}_{3}\right)$. But this is clear bearing in mind the presence of the second nitrogen atom $\mathrm{N} 1$ in the position para towards strongly electron donating amino group in the position 4. Such protonated arrangements are stabilized by the resonance and a para-quinoid form (Scheme 6) dominates in the resonance hybride. ${ }^{38,39}$

Generally, 4-aminoquinazoline derivatives (9a-i, 10a-g) substituted in the position 7 with electron donating groups are stronger bases than their 6-R isomers. In contrast, 4- $(N, N-$ dimethylamino)quinazolines (11a-g, 12a-g) substituted in the position 7 are weaker bases than 
their 6-R isomers. Such situation testifies to the different electron transfer in quinazolines with the bulky group in the position 4 .

Table 4. Dissociation constants $p K_{a}$ of three $4-(N, N$-dimethylamino)quinazoline series (11a-f, 12a-g, 13a-h)
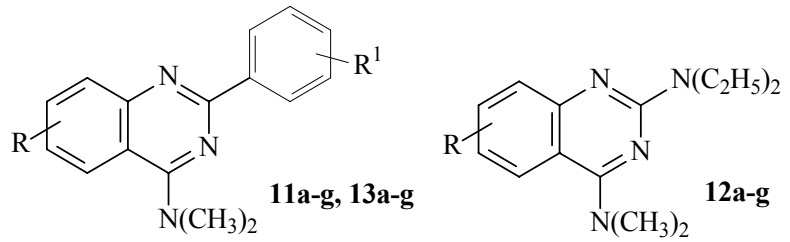

\begin{tabular}{|c|c|c|c|c|}
\hline Product & $R:$ & $R^{l}:$ & $\lambda_{\mathrm{ANAL}}[\mathrm{nm}]$ & $p K_{a}^{*}$ \\
\hline $11 \mathrm{a}$ & $\mathrm{H}$ & $\mathrm{H}$ & 262.5 & $6.31 \pm 0.07$ \\
\hline $11 b$ & $6-\mathrm{OCH}_{3}$ & $\mathrm{H}$ & 280.0 & $6.61 \pm 0.16$ \\
\hline $11 \mathrm{c}$ & $7-\mathrm{OCH}_{3}$ & $\mathrm{H}$ & 298.6 & $6.20 \pm 0.04$ \\
\hline 11d & $6-\mathrm{CH}_{3}$ & $\mathrm{H}$ & 272.3 & $6.52 \pm 0.12$ \\
\hline $11 \mathrm{e}$ & 7- $\mathrm{CH}_{3}$ & $\mathrm{H}$ & 232.5 & $6.35 \pm 0.02$ \\
\hline $11 f$ & $6-\mathrm{Br}$ & $\mathrm{H}$ & 320.0 & $5.88 \pm 0.16$ \\
\hline $11 \mathrm{~g}$ & $7-\mathrm{NO}_{2}$ & $\mathrm{H}$ & 236.6 & $4.42 \pm 0.25$ \\
\hline $12 \mathbf{a}$ & $\mathrm{H}$ & $\mathrm{H}$ & 279.0 & $8.88 \pm 0.09$ \\
\hline $12 b$ & 7-Cl & $\mathrm{H}$ & 277.8 & $7.94 \pm 0.13$ \\
\hline $12 \mathrm{c}$ & $6-\mathrm{Cl}$ & $\mathrm{H}$ & 255.7 & $7.91 \pm 0.05$ \\
\hline $12 d$ & $7-\mathrm{OCH}_{3}$ & $\mathrm{H}$ & 252.8 & $8.83 \pm 0.08$ \\
\hline $12 \mathrm{e}$ & $6-\mathrm{OCH}_{3}$ & $\mathrm{H}$ & 252.0 & $8.98 \pm 0.05$ \\
\hline $12 f$ & $7-\mathrm{NO}_{2}$ & $\mathrm{H}$ & 257.8 & $6.68 \pm 0.14$ \\
\hline $12 \mathrm{~g}$ & $6-\mathrm{NO}_{2}$ & $\mathrm{H}$ & 294.0 & $6.63 \pm 0.06$ \\
\hline $13 \mathbf{a}$ & $\mathrm{H}$ & $4-\mathrm{OCH}_{3}$ & 322.0 & $6.62 \pm 0.05$ \\
\hline $13 b$ & $\mathrm{H}$ & $4-\mathrm{CH}_{3}$ & 287.0 & $6.40 \pm 0.08$ \\
\hline $13 \mathrm{c}$ & $\mathrm{H}$ & $3-\mathrm{CH}_{3}$ & 283.0 & $6.28 \pm 0.06$ \\
\hline $13 d$ & $\mathrm{H}$ & $4-\mathrm{Cl}$ & 287.0 & $5.88 \pm 0.09$ \\
\hline $13 \mathrm{e}$ & $\mathrm{H}$ & $3-\mathrm{Cl}$ & 279.0 & $5.54 \pm 0.05$ \\
\hline $13 f$ & $\mathrm{H}$ & $4-\mathrm{NO}_{2}$ & 285.0 & $4.52 \pm 0.01$ \\
\hline $13 \mathrm{~g}$ & $\mathrm{H}$ & $3-\mathrm{NO}_{2}$ & 309.0 & $4.94 \pm 0.02$ \\
\hline
\end{tabular}

* The measurements were made in 50\% methanol-water solution in room temperature. 


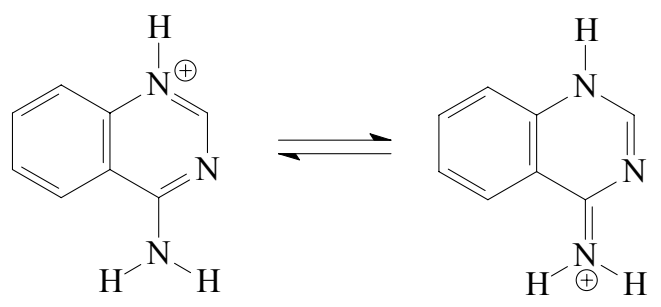

\section{Scheme 6}

The $p K_{a}$ values of the considered quinazolines were correlated with appropriate Hammett $\sigma$ constants. In the case of 4-aminoquinazoline derivatives $(9 \mathbf{a}-\mathbf{i}, \mathbf{1 0 a}-\mathbf{g})$ the best correlations were obtained applying $\sigma_{m}$ Hammett constants for 6-R substituted derivatives and $\sigma_{p}$ Hammett constants for 7-R substituted derivatives (Table 5, Figure 3). The application of this correlation type is consistent with Charton's suggestions, ${ }^{33}$ the investigations on electron interactions in monosubstituted alternating systems ${ }^{34}$ and our earlier studies connected with isoquinolines. ${ }^{19,20}$

A typical correlation was obtained in the case of 2-phenyl-4-( $N, N$-dimethylamino)quinazoline derivatives substituted in the position meta and para of the phenyl group (11a, 13a-g).

Table 5. Results of $p K_{a}$ vs $\sigma$ correlations for two 4-aminoquinazoline (9a-i, 10a-g) series

\begin{tabular}{llllllll}
\hline Entry & Product & Correlation type & Equation & $\boldsymbol{p} \boldsymbol{K}_{\boldsymbol{a}}=\boldsymbol{\rho} \boldsymbol{\sigma}+\boldsymbol{p} \boldsymbol{K}_{\boldsymbol{0}}$ & $\mathrm{S}^{\mathrm{a})}$ & $\mathrm{r}^{\mathrm{b})}$ & $\mathrm{n}^{\mathrm{c})}$ \\
\hline $1^{\mathrm{d})}$ & $\mathbf{9 a - i}$ & 6-R- $\sigma_{\mathrm{m}}, 7-\mathrm{R}-\sigma_{\mathrm{p}}$ & $p K_{a}=-1.188 \sigma+5.317$ & 0.132 & 0.962 & 9 \\
2 & 9a-i & 6-R- $\sigma_{\mathrm{p}}, 7-\mathrm{R}-\sigma_{\mathrm{m}}$ & $p K_{a}=-1.231 \sigma+5.352$ & 0.273 & 0.871 & 9 \\
$3^{\mathrm{d})}$ & $\mathbf{1 0 a}-\mathrm{g}$ & 6-R- $\sigma_{\mathrm{m}}, 7-\mathrm{R}-\sigma_{\mathrm{p}}$ & $p K_{a}=-2.335 \sigma+7.794$ & 0.170 & 0.985 & 7 \\
4 & $\mathbf{1 0 a}-\mathrm{g}$ & 6-R $-\sigma_{\mathrm{p}}, 7-\mathrm{R}-\sigma_{\mathrm{m}}$ & $p K_{a}=-2.088 \sigma+7.730$ & 0.464 & 0.880 & 7 \\
\hline
\end{tabular}

${ }^{a} \mathrm{~S}$ - residual sum of squares. ${ }^{\mathrm{b}} \mathrm{r}$ - correlation coefficient. ${ }^{\mathrm{c}} \mathrm{n}$ - number of data points used.

${ }^{\mathrm{d}}$ best correlations presented in Figure 2. 


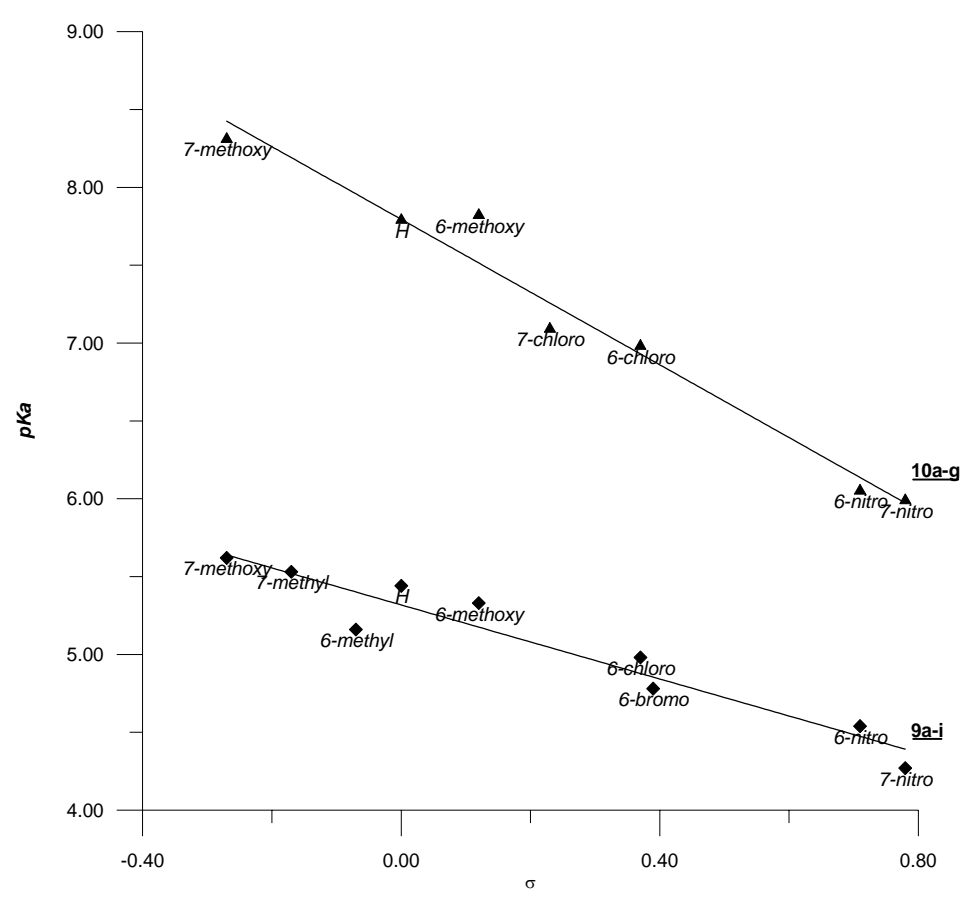

Figure 2. Correlation of $\sigma$ Hammett's constants with $p K_{a}$ for 4-aminoquinazolines (9a-i, 10a-g).

Table 6. Results of $p K_{a}$ vs $\sigma$ correlations for three 4- $N, N$-dimethylaminoquinazoline (11a-g, 12ag, 13a-g) series

\begin{tabular}{llllllll}
\hline Entry & Product & Correlation type & Equation & $\boldsymbol{p} \boldsymbol{K}_{\boldsymbol{a}}=\boldsymbol{\rho} \boldsymbol{\sigma}+\boldsymbol{p} \boldsymbol{K}_{\boldsymbol{0}}$ & $\mathrm{S}^{\mathrm{a})}$ & $\mathrm{r}^{\mathrm{b})}$ & $\mathrm{n}^{\mathrm{c})}$ \\
\hline $1^{\mathrm{d})}$ & 11a,13a-g & 4-R- $\sigma_{\mathrm{p}}, 3-\mathrm{R}-\sigma_{\mathrm{m}}$ & $p K_{a}=-1.895 \sigma+6.173$ & 0.127 & 0.988 & 8 \\
$2^{\mathrm{d})}$ & 11a,13a-g & 4-R- $\sigma_{\mathrm{m}}, 3-\mathrm{R}-\sigma_{\mathrm{p}}$ & $p K_{a}=-1.913 \sigma+6.270$ & 0.381 & 0.886 & 8 \\
$3^{\mathrm{d}}$ & $\mathbf{1 1 a - g}$ & 6-R- $\sigma_{\mathrm{p}}, 7-\mathrm{R}-\sigma_{\mathrm{m}}$ & $p K_{a}=-2.246 \sigma+6.218$ & 0.199 & 0.970 & 7 \\
4 & $\mathbf{1 1 a - g}$ & 6-R- $\sigma_{\mathrm{m}}, 7-\mathrm{R}-\sigma_{\mathrm{p}}$ & $p K_{a}=-1.747 \sigma+6.236$ & 0.441 & 0.844 & 7 \\
$5^{\mathrm{d})}$ & $\mathbf{1 2 a - g}$ & 6-R- $\sigma_{\mathrm{p}}, 7-\mathrm{R}-\sigma_{\mathrm{m}}$ & $p K_{a}=-2.550 \sigma+8.685$ & 0.320 & 0.957 & 7 \\
6 & $\mathbf{1 2 a - g}$ & 6-R- $\sigma_{\mathrm{m}}, 7-\mathrm{R}-\sigma_{\mathrm{p}}$ & $p K_{a}=-2.482 \sigma+8.666$ & 0.401 & 0.931 & 7 \\
\hline
\end{tabular}

${ }^{a} \mathrm{~S}$ - residual sum of squares. ${ }^{\mathrm{b}} \mathrm{r}$ - correlation coefficient. ${ }^{\mathrm{c}} \mathrm{n}$ - number of data points used. ${ }^{\mathrm{d}}$ best correlations presented at the Figure 3. 


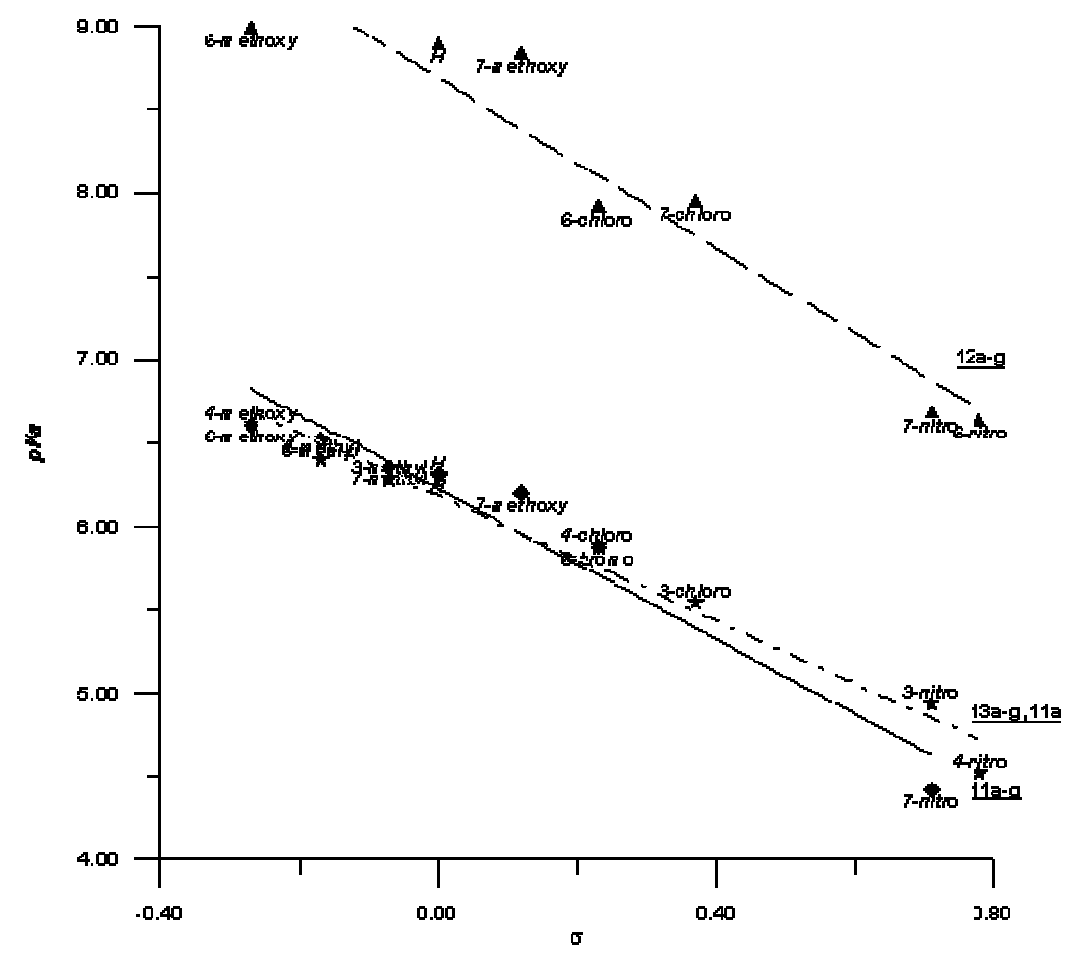

Figure 3. Correlation of $\sigma$ Hammett's constants with $p K_{a}$ for 4- $N, N$-dimethylaminoquinazolines (11a-g, 12a-g, 13a-g).

This group of compounds is closely related to the Hammett type - electrons are transfered from the substituents to the protonation site through the benzene ring and it is free from the steric interactions. The application of $\sigma_{p}$ constants for 2-(para- $\mathrm{R}^{1}$-phenyl) substituted derivatives and $\sigma_{m}$ constants 2 -(meta- $\mathrm{R}^{1}$-phenyl) substituted derivatives gives satisfactory results (correlation coefficient $\mathrm{r}=0.988$; Table 6 , Figure 3). The untypical correlation was obtained in the case of 6 and 7 substituted 4-( $N, N$-dimethylamino)quinazolines (11a-g, 12a-g). The application of $\sigma_{p}$ constants for 6-R substituted derivatives and $\sigma_{m}$ constants for 7-R substituted compounds gives satisfactory results (Figure 3; Table 6) though it is not consistent with the previously presented ideas (Table 5, Figure 2). This is the first stated case where the reversed electron effect transfer takes place in a bicyclic benzo-fused heteroaromatic system, opposite to alternating systems. It is true that deviations from electron interactions in alternating systems were observed earlier in series of the 1-methyl-4-phenyl-2-quinazolinone compound substituted in the 6 position where the correlation analysis between the half neutralization potential gives satisfactory results when Hammett $\sigma_{p}$ constants are used. $^{40}$

In our opinion such situation is the result of the steric hindrace of the bulky group in the 4quinazoline position. The primary steric effect which is connected with the interaction of the substituent in 2 or 4 position with free electron pairs of the ring nitrogen atoms should not be of the great importance. The secondary steric effect interpreted as the interaction between a large substituent in the 4 quinazoline position with a hydrogen atom in the 5 position becomes important here. Contrary to 1-(N,N-dimethylamino)isoquinolines where the secondary steric 
effect causes twisting of the big group from the ring plane and finally decreases the basicity, the opposite effect is noticed in the case of 4-(N,N-dimethylamino)quinazolines (11a-g, 12a-g, Scheme 7). A strong resonance stabilization of the protonated 4-( $N, N$-dimethylamino)quinazolines which involves $\mathrm{N} 1$ ring nitrogen atom to form a very stable para-quinoid structure prevent the twisting of the dimethylamino group from the ring plane. 4- $(N, N-$ Dimethylamino)quinazolines are indeed stronger bases than their counterparts unsubstituted at the amino group (Scheme 5).
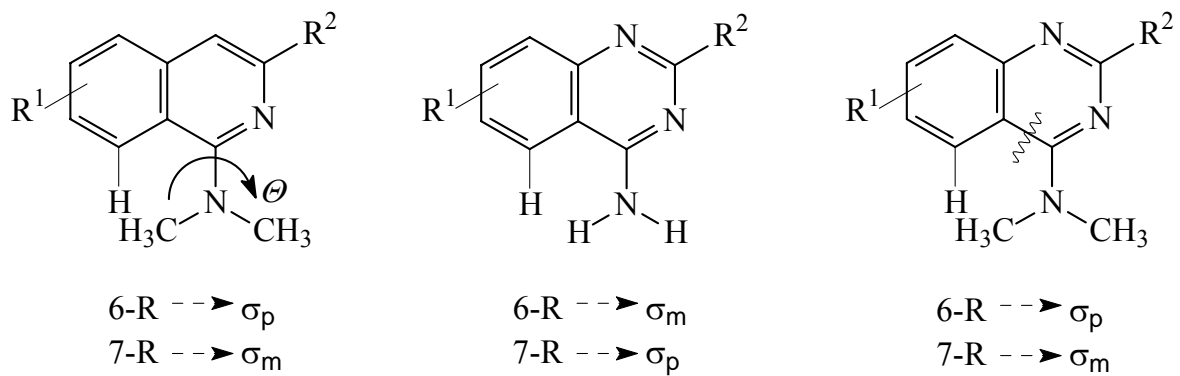

\section{Scheme 7}

Single crystal X-ray diffraction analysis of 7-methoxy-2-( $N, N$-dimethylamino)-4-( $N, N$ dimethylamino)quinazoline hydrochloride ${ }^{26}(\mathbf{1 2 d} \cdot \mathbf{H C l}$, Table 7$)$ testifies that the tendency of the arrangement to the steric hindrance minimalization is expressed by the C4-C4a lenghtening. This bond measures $1.455 \AA$ and is thus considerably longer than that in the corresponding quinazoline $^{14}(1.410 \AA)$.

Table 7. Selected bond lengths $(\AA)$ for quinazoline and its derivatives taken from MNDO calculations and X-ray structure analysis

\begin{tabular}{|c|c|c|c|c|c|}
\hline $\begin{array}{l}\text { Selected bond } \\
\text { method }\end{array}$ & $\begin{array}{l}\text { Quinazoline } \\
X \text {-ray }\end{array}$ & $\begin{array}{l}\text { Quinazoline } \\
M N D O\end{array}$ & $\begin{array}{l}\text { 13a } \\
M N D O\end{array}$ & $\begin{array}{l}\mathbf{1 2 \mathbf { a }} \\
M N D O\end{array}$ & $\begin{array}{l}\mathbf{1 2 d} \\
X-r a y\end{array}$ \\
\hline $\mathrm{N} 1-\mathrm{C} 2$ & 1.310 & 1.331 & 1.339 & 1.349 & 1.348 \\
\hline $\mathrm{C} 2-\mathrm{N} 3$ & 1.351 & 1.383 & 1.330 & 1.388 & 1.328 \\
\hline N3-C4 & 1.307 & 1.327 & 1.347 & 1.333 & 1.338 \\
\hline $\mathrm{C} 4-\mathrm{N}\left(\mathrm{CH}_{3}\right)_{2}$ & - & - & 1.403 & 1.437 & 1.342 \\
\hline $\mathrm{C} 2-\mathrm{R}^{1}$ & - & - & 1.488 & 1.395 & 1.346 \\
\hline $\mathrm{C} 4-\mathrm{C} 4 \mathrm{a}$ & 1.410 & 1.441 & 1.461 & 1.445 & 1.455 \\
\hline C8a-N1 & 1.372 & 1.381 & 1.373 & 1.372 & 1.393 \\
\hline
\end{tabular}

Moreover, these data concerning the analysis of single crystal X-ray diffraction have been corroborated by MNDO calculations for 4-(N,N-dimethylamino)-2-phenylquinazoline (11a) and its hydrochloride ${ }^{27}$ where the calculated bond lenghts are $1.461 \AA$ and $1.445 \AA$. The shortening of the $\mathrm{C} 4-\mathrm{N}\left(\mathrm{CH}_{3}\right)_{2}$ bond (1.342 $\AA$, Table 7) could also testify to the presence of a strong 
coupling of the free electron pair of the dimethylamino group with N1 ring nitrogen atom. Moreover, diethylamino group in the position 2 is also involved to the coupling but less stable ortho-quinoid form has a lower contribution in the resonance hybride. In the result $\mathrm{C} 2-\mathrm{R}$ bond $(1.346 \AA)$ is a little longer than $\mathrm{C} 4-\mathrm{N}\left(\mathrm{CH}_{3}\right)_{2}$ bond.

In that case the electron effects of the substituents in the benzene ring of the 4- $(N, N-$ dimethylamino)-2- $\mathrm{R}^{1}$-quinazoline derivatives are mostly transfered by the C8a-N1 bond. The length of the C8a-N1 is similar to that in the unsubstituted quinazoline and indicates delocalized bond feature. Thus the electron transfer in these systems (11a-g, 12a-g) occurs in the same way as in substituted aniline, where the substituents in the 4 position correspond to those in the 6 position of the quinazoline system and are well correlated with the Hammett $\sigma_{p}$ constants. The substituents in position 3 of aniline correspond to quinazoline substituents in the 7 position and are correlated with the Hammett $\sigma_{m}$ constants.

The values of correlation coefficients $\mathrm{r}$ (Table 4, 5, 6) obtained for 4-(N,N-dimethylamino)-2-

$\mathrm{R}^{1}$-quinazoline derivatives which are not very high $\left(\mathrm{R}^{1}=\mathrm{C}_{6} \mathrm{H}_{5}, \mathbf{1 1 a}-\mathbf{g}, \mathrm{r}=0.970 ; \mathrm{R}^{1}=\mathrm{N}\left(\mathrm{C}_{2} \mathrm{H}_{5}\right)_{2}\right.$, 12a-g, $\mathrm{r}=0.957$ ) could be caused in our opinion by two reasons. One of them is that part of electronic effects of the substituents presented in the benzene ring could be also transfered to pyrimidine ring through $\mathrm{C} 4-\mathrm{C} 4 \mathrm{a}$ bond. It could also mean that there is not one specifically defined protonation site in such arrangements.

\section{Conclusions}

Correlation analyses of $p K_{a}$ dissociation constants with Hammett $\sigma$ constants clearly show that the steric effects of the bulky substituents neighbouring the protonated ring nitrogen atom influence the electron transfer in the arrangement. The bulky substituents in the position 1 of isoquinoline derivatives are twisted from the ring plane and the contribution of the resonance effect in the entire electronic effect interacted by these substituents decreases. That is why the arrangements with the big and strongly electron donating groups are weaker bases in comparison with those with small groups. In contrast to isoquinolines the aromacity disturbance of the heterocyclic system is observed in quinazoline derivatives with the bulky substituents in the position 4. The strong resonance stabilization of the protonated 4- $(N, N-$ dimethylamino)quinazolines which involves N1 ring nitrogen atom to form very stable paraquinoid structure prevent the twisting of the dimethylamino group from the ring plane. Therefore the tendency of the arrangement to the steric hindrance minimalization is expressed by the C4$\mathrm{C} 4 \mathrm{a}$ weakening. In consequence the effect of the electron transfer through this bond is considerably limited and the untypical correlations between $p K_{a}$ values and $\sigma$ parameters are obtained. 


\section{Experimental Section}

General procedures. UV spectra were recorded on a Shimadzu UV-2102 spectrophotometer; basic medium: $0.05 \mathrm{M} \mathrm{NaOH}$ in $50 \%$ aqueous methanol solution, acidic medium: $0.05 \mathrm{M} \mathrm{HCl}$ in $50 \%$ aqueous methanol solution. Elemental analysis was carried out with a Perkin Elmer 240c analyser. The ${ }^{1} \mathrm{H}-\mathrm{NMR}$ spectra were recorded on a Varian Inova 300 spectrometer in DMSO solution using TMS as internal standard. MS spectra were obtained with a Shimadzu QP-200 mass spectrometer. Thin layer chromatography was carried out on silica gel $60 \mathrm{~F}_{254}$ (Merck) thin layer chromatography plates using a benzene-ethyl acetate mixture $(3: 1 \mathrm{v} / \mathrm{v})$ as the mobile phase. MNDO calculations have been carried out by means of the WinMopac V2.0 program.

1-amino-3-( $N, N$-diethylamino)isoquinoline $\left(5 ; \mathbf{C}_{13} \mathbf{H}_{17} \mathbf{N}_{3}\right)$. was synthesized accord -ing to the procedure given in ${ }^{20}$. Yield: $75 \%$; b.p.: $144-146^{\circ} \mathrm{C} / \mathrm{Torr} ; \mathrm{R}_{\mathrm{f}}=0.64 ;{ }^{1} \mathrm{H}-\mathrm{NMR}: \delta=1.17(6 \mathrm{H}, \mathrm{t}$, $\left.\mathrm{CH}_{2} \mathrm{C}_{3}\right), 3.43\left(4 \mathrm{H}, \mathrm{q}, \mathrm{C}_{2} \mathrm{CH}_{3}\right), 4.36\left(2 \mathrm{H}, \mathrm{s}, \mathrm{NH}_{2}\right), 7.17(1 \mathrm{H}, \mathrm{s}, \mathrm{H}-4), 7.24-7.31$ (2H, m, H-6, H-7), $7.81(1 \mathrm{H}, \mathrm{d}, \mathrm{J}=7.8 \mathrm{~Hz}, \mathrm{H}-5), 7.92(1 \mathrm{H}, \mathrm{d}, \mathrm{J}=7.8 \mathrm{~Hz}, \mathrm{H}-8)$ ppm; UV: $\lambda_{\max }\left(\varepsilon^{*} 10^{-3}\right)=$ acidic: 209.0 (14.44), 247.2 (9.53), 306.8 (3.97), basic: 209.8 (14.70), 244.0 (10.56), 308.2 (5.16) nm; MS: $m / z(\%)=215\left(\mathrm{M}^{+}, 85\right)$; Anal. Calcd. for $\mathrm{C}_{13} \mathrm{H}_{17} \mathrm{~N}_{3}: \mathrm{C}, 72.52 ; \mathrm{H}, 7.97 ; \mathrm{N}, 19.51$. Found: $\mathrm{C}$, $72.46 ; \mathrm{H}, 8.04 ; \mathrm{N}, 19.50 . p K_{a} 7.24 \pm 0.18\left(\lambda_{\mathrm{ANAL}}=246 \mathrm{~nm}\right)$.

$p \boldsymbol{K}_{\boldsymbol{a}}$ Measurements. The determination of the $p K_{a}$ dissociation constants was performed according to the spectrophotometric method of Albert and Serjeant ${ }^{31}$ in $50 \%$ aqueous methanol solution $\left(10^{-5} M\right.$, room temperature) (Table $\left.1,3,4\right)$.

\section{References}

1. Armarego, W. L. F. Fused Pyrimidines: Part I-Quinazolines; Interscience Publishers: New York-London-Sydney, 1967.

2. Kametani, T.; Fukumoto, K. Isoquinolines Part 1; John Wiley: New York, 1981; Vol. 38.

3. Fry, D. W.; Kraker, A. J.; McMichael, A.; Ambroso, L. A.; Nelson, J. M.; Leopold, W. R.; Connors, R. W.; Bridges, A. J. Science 1994, 265, 1093.

4. Traxler, T. M.; Furet, P.; Melt, H.; Buchdunger, E.; Meyer, T.; Lydon, N. J. Med. Chem. 1996, 39, 2289.

5. Hynes, J. B.; Tomazić, A.; Kumar, A.; Kumar, V.; Freisheim, J. H. J. Heterocycl. Chem. 1991, 28, 1981.

6. Harris, N. V.; Smith, C.; Bowden, K. J. Med. Chem. 1992, $27,7$.

7. Dempcy, R. O.; Skibo, E. B. Biochemistry 1991, 30, 8480.

8. Neumeyer, J. L; Weinhardt, K. K.; Carrano, R. A.; McCurdy, D. H. J. Med. Chem. 1973, 16, 808.

9. Irvin, J. L.; Irvin, E. M. J. Am. Chem. Soc. 1947, 69, 1091.

10. Craig, D. P.; Short, L. N. J. Chem. Soc. 1945, 419. 
11. Steck, E. A.; Ewing, G. W. J. Am. Chem. Soc. 1948, 70, 3397.

12. Craig, J. C.; Pearson, D. E. J. Heterocycl. Chem. 1968, 5, 531.

13. Albert, A. Physical Methods in Heterocyclic Chemistry; A. R. Katritzky Academic Press: New York, 1963; Vol.1, p 73.

14. Katritzky, A. R.; Rees, C. W.; Scriven, E. F. V. Comprehensive Heterocyclic Chemistry II; Elsevier Science Ltd: 1996; Vol. 6.

15. Armarego, W. L. F.; Smith, J. I. C. J. Chem. Soc. 1966, 234.

16. Perrin, D. D. Dissociation Constants of Bases in Aqueous Solutions; Butterworths: London, 1965, p 240.

17. Albert, A.; Armarego, W. L. F.; Smith, J. I. C. J. Chem. Soc. 1965, 5360.

18. Armarego, W. L. F. J. Chem. Soc. 1962, 561.

19. Zieliński, W.; Kudelko, A.; Mazik, M. Polish J. Appl. Chem. 1995, 39, 33.

20. Perrin, D. D. J. Chem. Soc. 1965, 5590.

21. Zieliński, W. Polish J. Chem. 1989, 63, 233.

22. Zieliński, W.; Mazik, M. Heterocycles 1994, 38, 375.

23. Zieliński, W. Synthesis 1980, 70.

24. Zieliński, W.; Kudelko, A. Monatsh. Chem. 2003, 134 (3), 403.

25. Zieliński, W.; Kudelko, A.; Holt, E. M. Heterocycles 1996, 43, 2101.

26. Zieliński, W.; Kudelko, A.; Holt, E. M. Heterocycles 1998, 48, 319.

27. Zieliński, W.; Kudelko, A. Monatsh. Chem. 2000, 131, 733.

28. Zieliński, W.; Kudelko, A. Monatsh. Chem. 2000, 131, 895.

29. Zieliński, W.; Kudelko, A. J. Heterocycl. Chem. 2002, 39, 1289.

30. Kudelko, A.; Zieliński, W. J. Heterocycl. Chem. 2004, 41, 247.

31. Albert, A.; Serjeant, E. P. Ionization Constants of Acids and Bases; Methuen\&Co Ltd: New York, 1962; p 69.

32. Shorter, J. Correlation Analysis in Organic Chemistry; Clarendon Press: Oxford, 1973.

33. Charton, M. J. Org. Chem. 1965, 30, 3341.

34. Dewar, M.; Dougherty, R. The PMO Theory of Organic Chemistry; New York, 1975; pp 99110.

35. Rasała, D. Bull. Soc. Chim. Fr. 1992, 129, 79.

36. Witanowski, M. Wiad. Chem. 1988, 12, 113; Chem. Abstr. 1989, 110, 134358w.

37. Joule, J. A.; Smith, G. F. Chemistry of Heterocyclic Compounds, Van Nostrand Reinhold: London-New York-Cincinati-Toronto-Melbourne, 1978.

38. Essery, J. M.; Schofield, K. J. Chem. Soc. 1961, 3939.

39. Essery, J. M.; Schofield, K. J. Chem. Soc. 1963, 2225.

40. Wulfert, E.; Bolla, P.; Mathieu, J. Chimie Therapeutique 1969, 4, 1969. 